\title{
Analysis of Radioactivity Content in Sediment, Water and Fish Collected From Rajakkamangalam Estury of Kanyakumari District in Tamilnadu, India
}

\author{
P. NandhaKumari ${ }^{1}$, A.TamilSelvi ${ }^{2}$, V. Sarojini ${ }^{3}$ A.Palavesam ${ }^{4}$ \\ ${ }^{l}$ Asst.Professor Dept. of Zoology,Lekshmipuram College of Arts \& Science, Neyyoor \\ ${ }^{2}$ Associate Professor Dept.of Zoology, Lekshmipuram College of Arts \& Science, Neyyoor \\ ${ }^{3}$ Asst.Professor Dept. of Physics, Lekshmipuram College of Arts \& Science, Neyyoor \\ ${ }_{4}$ Professor CMST Rajakkamangalam
}

\begin{abstract}
The natural radioactivity due to Uranium, Thorium and Potassium in soil, and water contributes to the radiation dose received by human beings significantly. For assessing the environmental radiological impact to the public it is essential to evaluate the activity levels of these nuclides. Results of the gamma ray spectrometric measurements, carried out for natural radioactivity levels due to ${ }^{226} \mathrm{Ra},{ }^{226} \mathrm{Th},{ }^{40} \mathrm{~K}$, and alpha, beta activity levels in sediment, water and fish collected from Rajakkamangalamestury were determined. The alpha and beta activities are found to be greater in sediment with $114.764 \mathrm{~Bq} / \mathrm{kg}$ and $357.25 \mathrm{~Bq} / \mathrm{kg}$ respectively.

The ${ }^{40} \mathrm{~K}$ potassium content is found to be higher in fish with $73.81 \mathrm{~Bq} / \mathrm{kg}$ than in sediment and water. The results of these investigations are discussed detail in this paper.
\end{abstract}

Keywords:Radioactive nuclides, sediment, water, fish

\section{Introduction}

Exposure to ionizing radiation from natural sources is a continuous and unavoidable feature to life on earth. It is an established fact that the radioactivity is harmful to living beings, however small it may be. Many areas in the world such as Australia, Brazil, China, India, Iran, Japan etc., possess levels of natural radiation. The most important places among the well documented Natural HighBackground Radiation Areas (NHBRA) of the world inhabited by largepopulations are Gurapari in Brazil [1], Yangjiang in China [2], Chavara and Manavalakurichy in India [3] and Ramsar in Iran [4-6]. Natural radiationlevels in this region are higher than normal which are believed to be emitted from the rich deposits of the monazite bearing black sands. The mineral monazite contains radioactive elements which is the main cause for natural radiation in the South West Costal belt. The important localities possessing high radioactivity levels along the South West Coastal belt are the Chavara - Neendakara in Kerala Coast, and the Muttom - Midalam in the Southern TamilNadu Coast. Because the earth's bedrock contains varying amounts of radioactive elements the amount of radioactive elements and radioactivity level in water also varies. In the recent years studies on high natural background radiation areas in the world have been of prime importance for risk estimation due to long term low level whole body radiation exposures to the public with the increased public concern over radiation safety. The studies on Natural background radiation areas provide a good scope for evaluating biological effects caused by radiation exposure on a long term basis. Measurements of radioactivity were made in sediment, water and fish collected from Rajakkamangalamestury which is $7 \mathrm{kms}$ from Muttom a naturally High Background Radiation Area (NHBRA) in Kanyakumari district of TamilNadu India. The details of the findings are discussed in this paper.

Study Area

\section{Materials And Methods}

The study area is Rajakkamangalamestury near Centre for Marine Science and Technology(CMST) which is nine kms from Nagercoil, the capital of Kanyakumari district and is $7 \mathrm{kms}$ nearer to Muttom a Naturally High Background Area (NHBRA) of Kanyakumari District along the South Coastal region of Tamil Nadu. 


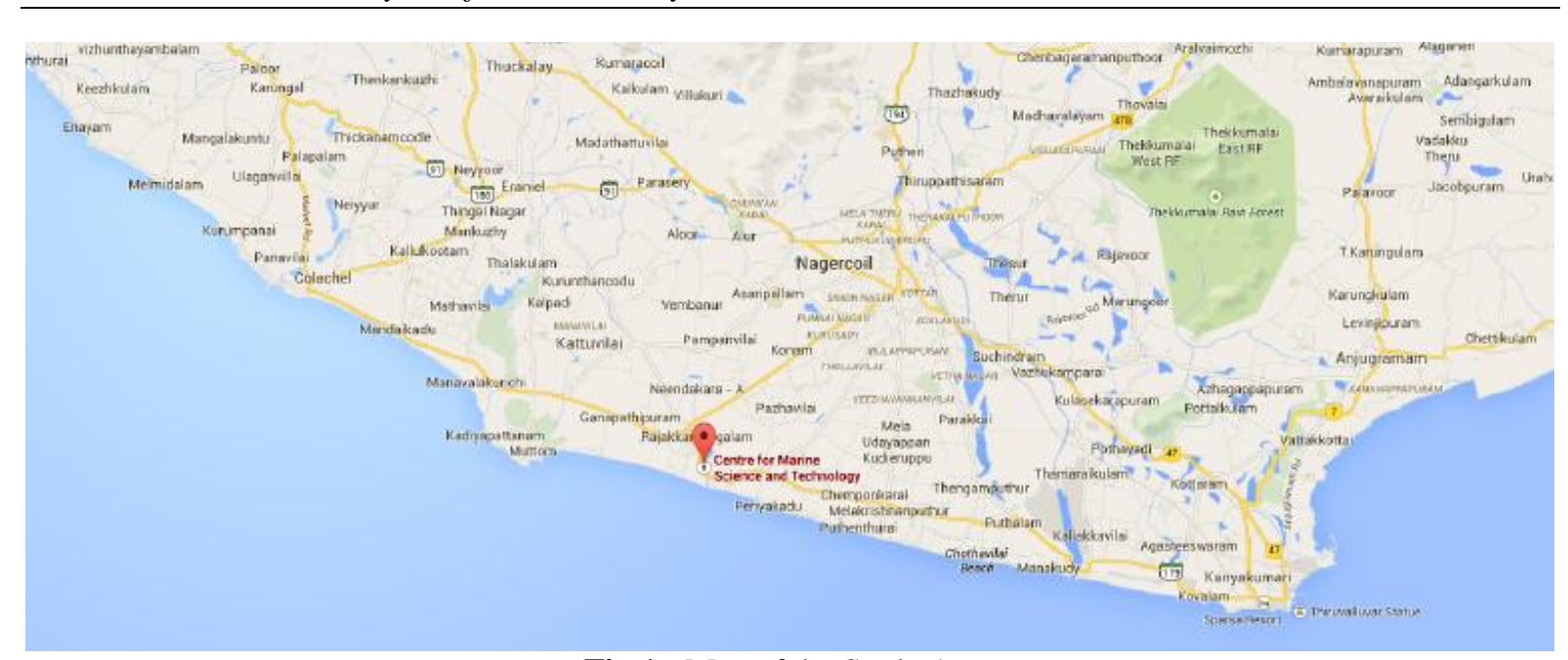

Fig 1 : Map of the Study Area

\section{Sediment:}

\section{Sample Processing And Activity Determination}

About $1 \mathrm{~kg}$ of sediment from the study area is taken and is dried in an oven at a temp of $150^{\circ} \mathrm{c}$ for 4 hours. The sample is powdered with the help of agate mortar. The powdered sample is ready for radioactive analysis. Alpha, beta and gamma radiations present in the sample was determined using alpha counting system, beta counting system and Gamma ray spectrometer respectively.

\section{Water}

10 litre of water is taken and filtered using Whattmann filter paper. To the filtered water, $10 \mathrm{ml}$ of $10 \%$ potassium dihydrogen orthophosphate, $2 \mathrm{ml}$ of $\mathrm{Cacl}_{2}$ and ammonia solution is added and is left for a night. Decand the supernatant liquid and dissolve the precipitate in con.Hcl. Reduce the volume and add $1 \mathrm{ml}$ of Con. $\mathrm{H}_{2} \mathrm{So}_{4}$ and $1 \mathrm{ml}$ of barium carrier. $\mathrm{BaSo}_{4}$ Precipitate is taken in a clean and dry planchet and it is ready for analysis.

\section{Fish}

For fish about 2 gms of fish [ Oreochromismossambicus species] was collected from study area. It was washed thoroughly with water and cut into pieces and dried in hot air oven at a temperature of about $150^{\circ} \mathrm{C}$ for four hours. The sample is taken in a silica crucible and ashed it in muffle furnace at a temperature of about $600^{\circ} \mathrm{C}$ for 4 hours and the sample is ready for analysis by using respective counting system.

IV. Result And Discussion

Table : 1 Gross $\alpha$ activity in samples

\begin{tabular}{|l|l|l|}
\hline No & Sample & $\alpha$ activity \\
\hline 1 & Sediment & $114.764 \mathrm{~Bq} / \mathrm{kg}$ \\
\hline 2 & Water & $0.043 \mathrm{~Bq} / 1$ \\
\hline 3 & fish & $57.38 \mathrm{~Bq} / \mathrm{kg}$ \\
\hline
\end{tabular}

Table 2 : Gross $\beta$ activity in samples

\begin{tabular}{|l|l|l|}
\hline No & Sample & $\beta$ activity \\
\hline 1 & Sediment & $357.25 \mathrm{~Bq} / \mathrm{kg}$ \\
\hline 2 & Water & $0.28 \mathrm{~Bq} / \mathrm{l}$ \\
\hline 3 & fish & $123.67 \mathrm{~Bq} / \mathrm{kg}$ \\
\hline
\end{tabular}

Table 3 : Radioactive nuclides in Samples

\begin{tabular}{|l|l|c|c|c|c|}
\hline \multirow{2}{*}{ No } & Sample & \multicolumn{4}{|c|}{ Radioactive nuclides Bq/kg (or) Bq/1 } \\
\cline { 3 - 6 } & & ${ }^{226} \boldsymbol{R a}$ & ${ }^{228} \mathrm{Ra}$ & ${ }^{40} \mathrm{~K}$ & ${ }^{232} \boldsymbol{T h}$ \\
\hline 1 & Sediment & 128.37 & 103.45 & 28.36 & 1382.5 \\
\hline 2 & Water & 0.014 & 0.011 & 0.35 & 0.47 \\
\hline 3 & fish & 33.52 & 27.68 & 73.81 & 87.25 \\
\hline
\end{tabular}

From the results obtained in Table $1:$ it is evident that $\alpha$ activity is higher in sediment with 114.764 $\mathrm{Bq} / \mathrm{kg}$ than in water and fish with $0.043 \mathrm{~Bq} / \mathrm{l}$ and $57.38 \mathrm{~Bq} / \mathrm{kg}$ respectively. A same pattern of high $\beta$ activity was reported in sediment with $357.25 \mathrm{~Bq} / \mathrm{kg}$ while a mere $0.28 \mathrm{~Bq} / \mathrm{l}$ was estimated in water and $123.67 \mathrm{~Bq} / \mathrm{kg}$ 
in fish. Gamma activity measurements reveal that ${ }^{228} \mathrm{Ac}$ was $128.37 \mathrm{~Bq} / \mathrm{kg}$ in sediment, $0.014 \mathrm{~Bq} / \mathrm{l}$ in water and $33.52 \mathrm{~Bq} / \mathrm{kg}$ in fish. The activity concentration of $40 \mathrm{~K}$ in fish is higher with $73.81 \mathrm{~Bq} / \mathrm{kg}$ than in sediment and water with $28.36 \mathrm{~Bq} / \mathrm{kg}$ and $0.35 \mathrm{~Bq} / \mathrm{l}$ respectively. ${ }^{232} \mathrm{Th}$ was reported as $1382.5 \mathrm{~Bq} / \mathrm{kg}$ in sediment, 0.47 $\mathrm{Bq} / \mathrm{l}$ in water and $87.25 \mathrm{~Bq} / \mathrm{kg}$ in fish respectively.

\section{Conclusion}

The activity concentration of radioactive nuclides reported from this region are now found to be within the limit. Natural radioactivity forms a significant part of the total activity in the environment whereas anthropogenic activities have introduced significant amounts and usually their influence is limited to the near locality of their introduction. The presence of radioactivity in sediment and water is due to the deposition from atmosphere, leaching from soils and rock courses formed from dissolved ${ }^{226} R a$ and ${ }^{222} R a$.

\section{Reference}

[1]. T.L. Cullen, E. Renna Franca (Eds). Proceedings of the International Symposium on areas of high natural radioactivity. Published by AcademicaBrasileeradecieneias RJ,1977. Brazil. June, 16-20.

[2]. Y. Lin, C.Chen, Pel-Hou. Lin. Natural Background radiation dose assessment in Taiwan. Environ. Int. 22. 45-48 Radiat. Res. Vol, 152 no.6 Pp 145-148.

[3]. V. Mahadevan, G.R. Narayana Das, N. Nagarajarao. Prospecting and evaluation of beach placers along the coastal belt of India. In proceedings of II United Nations International conference on Peaceful uses of Atomic Energy, Vol.2. 1956. Pp 103-106.

[4]. M. Sohrabi. Recent radiological study of high level natural radiation areas of Ramsar. In proceedings of International conference Ramsar. 3(7), 1990. Pp 39 - 47.

[5]. B.G. Bennett. Natural background radiation exposure worldwide in Health levels of Natural Radiation. In proceedings of International Conference Ramsar, 3(7), 1990. Pp 18-30.

[6]. M. Ghiassi - Nejad, S.M. J. Mortazavi, J.R. Gameron. Very high background radiation areas of Ramsar, Iran. Preliminary biological studies, Health Phys. 82 (2002) 87-93.

[7]. UNSCEAR, Sources and Effects of Ionizing Radiation Report to United Nations Scientific Committee on the effect of Ionizing Radiation, United Nations, New York (2000).

[8]. Kannan V, Rajan M.P., Iyengar M.A.R. and Ramesh .R. Distribution of natural and anthropogenic, radionuclides in soil and beach sand samples of Kalpakkam (India) using high pure germanium (HpGe) gamma ray spectrometry. Appl.Rad. Isotopes, 57. 109-119 (2002).

[9]. Sarojini.V, Chithambarathanu.T. "Estimation of Radioactivity in Beach sands of Kanyakumari Coast, Tamil Nadu" Proceedings of NSRP - 19, Dec.12-14, 2012. Mamallapuram, TamilNadu India. Pp (447 - 448)

[10]. Narayana.Y,Somashekarappa.H.M., Karunakara.N.J.Avadhani D.N., Mahesh H.M.,Sidappa. K.Natural Radioactivity due to the soil samples of Coastal Karnataka of South India. Health Physics Society,80.2001.Pp.24-33. 